\title{
INCAÍSMO Y DECADENTISMO EN LOS CUENTOS DE ABRAHAM VALDELOMAR
}

\author{
Marta Ortiz Canseco \\ Universidad Internacional de La Rioja \\ marta.ortiz@unir.net
}

RESUMEN: Este texto trata de reivindicar, en la línea de Mónica Bernabé, la figura del peruano Abraham Valdelomar como un autor integral. Resulta más productivo hablar de este escritor observando su trayectoria en conjunto, que separar sus dos facetas, la del dandy y la del costumbrista. Desde este punto de partida, pretendemos realizar una lectura de algunas de sus narraciones, incidiendo en la importante resemantización que realiza de las corrientes literarias foráneas dentro del contexto cultural peruano de su época.

PALABRAS CLAVE: Abraham Valdelomar, decadentismo, capitalismo, Perú, incaísmo.

ABSTRACT: This text aims to provide a unified vision of two aspects of Abraham Valdelomar's short stories, which are usually read like opposites: his first stories with dandy characters are usually opposed to his latest costumbrist ones, where a Peruvian way of life would be claimed as the 'true' description of a national identity. Following Mónica Bernabé, we will read Valdelomar's narrations as a single and original project that tries to integrate the foreign literary forms within the Peruvian cultural context of his time.

KEYWORDS: Abraham Valdelomar, Decadentism, Capitalism, Perú, Incaism

$$
* * *
$$

Si el Perú tuvo algún poeta maldito en la estela de Poe, Baudelaire o Wilde, ese fue Abraham Valdelomar. Nacido en Ica en 1888, se le ha definido como el autor que “inaugura la profesión de escritor en el Perú" (Bernabé 2003: 42), en la medida en que fue el primero que pudo vivir de lo que escribía, así como de las conferencias que impartió a lo largo y ancho del país.

La división del trabajo que impone el sistema capitalista obliga al poeta de finales del siglo XIX a abandonar "la multiplicidad de funciones que justificaban y explicaban, más allá de la excelencia artística posible de sus obras, su lugar en la vida social y su papel histórico dentro de una determinada comunidad tradicional" (Rama 1985: 45). Efectivamente, con Darío y otros autores modernistas se clausura la figura del poeta romántico, aquel que mantenía un lugar prestigioso en la sociedad, y se empieza a ver al escritor como un paria cuya función dentro del sistema deja ya de tener sentido. El poeta debe ser ahora productivo, su labor debe servir para algo dentro de una sociedad crecientemente utilitarista. De este modo, al dar la espalda a sus antiguas funciones, el sistema exige al escritor que redefina su papel, que se especialice en una tarea concreta, algo difícil en el medio cultural latinoamericano de finales del siglo XIX, donde el neocolonialismo occidental imponía con fuerza un sistema de producción capitalista en una sociedad con claras costumbres y jerarquías precapitalistas. 
Es así como "los poetas se transformarán en los servidores, custodios, de dos valores siempre vagos y mal definidos —el ideal y la belleza-, agrupándose en una suerte de cofradía que se autoabastece" (Rama 1985: 47). Se trata de un doble movimiento que esconde una gran complejidad: si por un lado el poeta huye a su torre de marfil, expulsado por una sociedad que no ve ya en él ninguna utilidad, por otro lado deberá encontrar la forma de ganarse la vida en tanto productor de mercancías, la mercancía del arte.

Quien se pensaba y presentaba como artista era tanto un productor como un consumidor que tenía acceso a la historia completa de su arte y por lo tanto la capacidad de juzgar el sistema de elecciones formales que le ofrecía el mercado. Dadas estas premisas, el arte de escribir no requería solamente producir una obra literaria sino también producirse a sí mismo como artista (Nouzeilles 1998: 296).

En este sentido la antigua dignidad que se le atribuía al poeta desaparece, pues se convierte en un marginado, un vagabundo, un bohemio, un borracho. Como sabemos, muchos autores (los que conocemos como 'malditos') lograron revertir este movimiento, convirtiendo ese rol social precisamente en la faceta más productiva de su carrera. El artista abandona una identidad fija y comienza a representar varios papeles, convirtiendo su propia vida en obra de arte y la obra en una extensión de su vida. En un principio este movimiento es rompedor: el escritor se rebela, acude a imágenes contrarias al ideal burgués, renuncia a la salud y al higienismo, exalta la lucidez de enfermedades como la tuberculosis, etc. Pero tarde o temprano el sistema absorbe esta postura, el autor no escapa a la necesidad de ganarse la vida, de modo que mantiene una relación oscilante con el mercado consumidor: "necesitando de él por poderosas razones económicas y desconfiando simultáneamente, ya que se trataba de un ambiente desconocido, incógnito, cuyo comportamiento con la obra de arte resultaba siempre imprevisible y donde ella se sumía en un proceso muchas veces desvirtuador de sus esencias" (Rama 1985: 61).

En el Perú, Abraham Valdelomar constituye una figura paradigmática de este tipo de intelectual. Su origen iqueño es significativo, pues a pesar de que cursó su educación secundaria en Lima, la infancia en provincias marcará su vida y también el rumbo de las letras peruanas: en esta época comienzan a cobrar gran importancia las provincias frente a la capital. El trasladado a Lima de muchos de los artistas provincianos permitió establecer un diálogo entre las distintas ciudades del país que hasta entonces no existía. En ese sentido, podemos considerar a Valdelomar un precursor, por las 'giras' que realizó durante los dos últimos años de su vida; un intelectual verdaderamente moderno $\mathrm{y}$ antecesor de muchas actitudes y estilos de la generación posterior, la de los vanguardistas peruanos. Valdelomar no pertenece a ninguna gran familia aristocrática y solo gracias a su talento pudo insertarse en lo que ahora conocemos como el canon literario peruano.

'El conde de Lemos', como firmaba Valdelomar, se matriculó varias veces en la universidad de San Marcos, aunque nunca llegó a culminar sus estudios. Como Mariátegui y algunos otros autores de la época, Valdelomar fue un autodidacta. Ferviente defensor del presidente Guillermo Billinghurst, apoyó su victoria frente a Aspíllaga, en 1912. En 1913 viajó a Nueva York, París y Roma, como diplomático del gobierno de Billinghurst y a la caída de este volvió a su patria. En 1914 ganó el premio de literatura otorgado por La Nación, periódico de filiación billinghurista, por su cuento "El caballero Carmelo", en el que describe las peleas de gallos típicas de Ica, con un retrato aparentemente costumbrista pero de una intensa fuerza emotiva y con grandes intuiciones estéticas. 
Desde 1915, año en que se publica su novela La mariscala, Valdelomar publica sus artículos periodísticos en un par de secciones propias, "Palabras" y "Fuegos fatuos", para el periódico La Prensa, y más tarde colabora también en Sudamérica. En 1918 se publica una recopilación de cuentos bajo el título de El caballero Carmelo, ese mismo año ve la luz su ensayo sobre tauromaquia, Belmonte, el trágico, y póstumamente, en 1921, aparece otra colección de cuentos: Los hijos del sol. En los últimos años de su vida, Valdelomar realizó las citadas giras por las provincias peruanas, dando conferencias y recorriendo el país. Además, su actividad política renació en 1919, pues con la subida al poder de Augusto B. Leguía fue elegido diputado por Ica.

Esa Lima de comienzos del siglo XX, en la que Valdelomar pasó casi toda su juventud, constituía el punto de encuentro de la intelectualidad peruana. Alrededor de 1916 se inaugura en la capital el Palais Concert, lugar de encuentro de "los futuros 'colónidas', los niños góticos, la crema juvenil, formada en San Marcos, Guadalupe, La Recoleta, los jesuitas y... el fumadero del chino Aurelio, en la calle Hoyos" (Sánchez 1987: 168). Valdelomar, Mariátegui, Federico More, Pablo Abril del Vivero, Alejandro Ureta, César Vallejo..., todos ellos y muchos más participaban de las tertulias, paseos y reuniones diarios formados por el más heterogéneo grupo de intelectuales.

El retrato que ofrece Luis Alberto Sánchez de esta belle époque limeña - cuyo máximo esplendor sitúa entre los años 1915 y 1920 - refleja una ciudad en plena efervescencia cultural. La mayoría de los intelectuales pertenecían a la redacción de algún periódico, desde donde se ofrecía al público la actualidad y las polémicas culturales a diario. Como hemos mencionado, Valdelomar redactaba sus secciones propias en periódicos como La Prensa o Sudamérica, y del mismo modo Mariátegui colaboraba para El Tiempo, antes de inaugurar, junto a su compañero César Falcón, el diario La Razón. La labor cultural que Abraham Valdelomar llevó a cabo durante estos años es crucial, tanto para su propia trayectoria intelectual, como para el panorama de las letras peruanas del momento. En 1918 el artista iqueño comienza una gira para presentar conferencias en Trujillo, Piura, Cajamarca, Pacasmayo, Chiclayo y, más tarde, en su Ica natal y en Pisco. No debe pasarse por alto la importancia de que un intelectual de la talla de Valdelomar visitase tantas y tan variadas provincias, alejadas todas ellas de la capital, pues por primera vez existe el afán de incluir y agrupar a los artistas de todo el país en el movimiento intelectual de la época.

La fundación de la revista Colónida por parte de Valdelomar en 1916 supuso una de las primeras y más célebres manifestaciones de modernidad literaria en el Perú. Las tensiones entre los 'colónidas' y la generación de José de la Riva Agüero se reflejaron claramente en la revista de Valdelomar, pues sus redactores se sentían lejos de los intelectuales que hasta entonces acaparaban a la opinión pública.

Lo cierto es que en Colónida se libran no una sino varias polémicas, que a veces se confunden entre sí: entre dos grupos literarios de una misma generación; entre provincianos y limeños; entre quienes disponen del poder - social, político, económico y tienen acceso a los medios de información, y quienes se sienten excluidos o postergados; entre el conformismo y el anticonformismo, o entre la seriedad y la improvisación, según el punto de vista que se adopte (Loayza, 1990: 138).

Luis Alberto Sánchez afirmó que el cambio cultural producido en 1916 no habría sido posible sin la extraordinaria actitud receptiva y abierta del grupo reunido en torno a Colónida. Los encuentros de intelectuales y artistas de la época en el recién inaugurado Palais Concert dan lugar, entre otros acontecimientos culturales, a la creación de esta revista, que por su carácter innovador y su ávida búsqueda de una estética moderna permite que la definamos como uno de los puntos de partida de la nueva poesía peruana. 
Antes de ella, en junio de 1915, había aparecido la revista Cultura, dirigida por Enrique Bustamante y Ballivián, que reunía a grandes poetas e intelectuales de la época: en su primer número publicaron Manuel González Prada, Clemente Palma, Leonidas Yerovi, José María Eguren, Percy Gibson y Riva Agüero, entre otros. Aunque finalmente no participó como codirector, Valdelomar había comenzado el proyecto de la revista con Bustamante y Ballivián, de modo que Cultura supone el antecedente más claro y directo del nacimiento de Colónida, a pesar de su corta duración (solamente se publicaron tres números). Pero Valdelomar también estuvo vinculado a otras revistas anteriores, fundadas todas en 1915, como Lulú, dirigida por Carlos Pérez Cánepa, Alma Latina, por Guillermo Luna Cartland y Raúl Porras, o Rigoletto, por Darío Eguren Larrea (Sánchez, 1987).

Ninguna de ellas, sin embargo, logró tan alto alcance ni tan profunda resonancia como Colónida, cuyos únicos cuatro números aparecieron entre enero y mayo de 1916. Valdelomar es responsable de los tres primeros números, pero el último fue dirigido por Federico More, su compañero. Esta diferencia entre los tres primeros y el último número es significativa: los dirigidos por Valdelomar editan su portada con un dibujo de cada uno de los poetas a los que se rinde homenaje: José María Eguren, José Santos Chocano y Percy Gibson. El cuarto y último número, de obvios intereses políticos, ofrece la fotografía de Javier Pardo y Ugarteche, rector de la Universidad Mayor de San Marcos. Pero lo realmente valioso de la revista Colónida fueron las colaboraciones de sus componentes y, ante todo, las de su director, 'El Conde de Lemos', e incluso las de su amigo y discípulo 'Juan Croniqueur': un joven José Carlos Mariátegui en su faceta más desconocida, la del bohemio provocador y melancólico.

A pesar de la fama que ha cobrado la revista como promotora de una revolución estética, el crítico Luis Loayza (1990) ha analizado y puesto en duda la supuesta rebelión de Colónida. Según él, solo el homenaje al poeta José María Eguren resulta innovador, pues las otras menciones son a autores como Chocano, Percy Gibson o Ricardo Palma, ya consagrados en el panorama literario de entonces. También Mariátegui definió al grupo 'colónida' como rebelde, pero no revolucionario, pues supuso una insurrección contra el academicismo y la oligarquía, pero se caracterizó por el énfasis retórico y el gusto conservador.

Sea como sea, Valdelomar ha pasado a la historia como el dandy peruano y como representante y antecesor de toda una generación de intelectuales:

yo represento más que una persona y un hombre, yo represento el ideal de toda una generación y el ansia infinita de toda una raza. Yo no soy una persona, sino una idea; yo no soy un ciudadano, sino un ideal [...] Vibra en mí el eco de la Raza humillada, de pueblos escarnecidos, de la libertad encadenada... (cit. en Sánchez, 1987: 389). ${ }^{1}$

Valdelomar, como decíamos al comienzo, inaugura la profesión de escritor en su país; antes de él, "escribir y publicar libros era una actividad relacionada al dinero o a la posición social" (Bernabé 2003: 43). Se convirtió así en el "testimonio viviente de que, sin vender el alma al diablo, era posible vivir de la pluma, reconociéndosele su incomparable talento para proyectar hacia la esfera pública su labor de escritor" (Rénique 2015: 258). El hecho de que Valdelomar reivindique el talento frente al poder político constituye un acto de rebeldía inédito hasta entonces en el panorama literario peruano. Por otro lado, su pose de dandy y su estilo decadentista contrasta con la

\footnotetext{
${ }^{1}$ Discurso pronunciado antes de la victoria de Leguía y de su propio nombramiento como diputado por Ica, en 1919, en el Teatro Colón de Lima, con motivo del homenaje a los peruanos expulsados de los territorios conquistados por Chile en 1879. Publicado en Fénix, número 15, 1968.
} 
actividad política y el militarismo que acabamos de comentar. Su trayectoria, tal y como indica Nouzeilles (1998: 302), "presenta todos los signos de la modernización de la producción cultural y sus tensiones entre la pulsión política y la autonomía estética".

Sin embargo, no conviene separar al Valdelomar primero, autor de obras decadentistas como La ciudad de los tísicos o La ciudad muerta, ambas de 1911, del Valdelomar que publicó en 1918 los cuentos costumbristas y 'nacionalistas' de El caballero Carmelo, o el que en 1916 sacudió el panorama literario limeño con la publicación de Colónida. Podría afirmarse que la pose del poeta decadentista que vemos en las obras previas a sus viajes a Estados Unidos y Europa, en 1913, se convierte después en ardiente y dolorosa comprensión de su pueblo; el dandy no aparece ya en sus sencillos relatos costumbristas, en las nostálgicas descripciones de su pueblo natal, en la evocación de los indios, en la ironía con que trata el decadentismo occidental en los cuentos yanquis.

Tradicionalmente, la crítica ha insistido en separar estas dos facetas del autor, distinguiendo al "escritor frívolo, ingenuo, profesor de dandismo" del otro, "el verdadero, que se encuentra a sí mismo cuando su escritura logra dar con una veta criollista y melancólica" (Bernabé 2003: 42). Estuardo Núñez, por ejemplo, presenta los viajes de Valdelomar como el comienzo de su auténtica literatura: el conocimiento de su propio país a través del viaje "habría de ser sustancial para abandonar su limeñismo estéril y afirmar su nacionalismo integral" (Núñez 1991: 139). Tampoco Loayza se resiste a mencionar esta productiva dicotomía, señalando que el Valdelomar dandy es autor de gran parte de su obra, pero que existe "otro Valdelomar, el verdadero, el central, uno de nuestros más grandes escritores" (Loayza 2003: 18).

Este desdoblamiento, tal y como demuestra Bernabé, ha permitido a la crítica literaria reconciliar la figura de Valdelomar con una cierta idea de nacionalidad, el orgullo de la patria, la labor social del escritor, dejando a un lado esa etapa primera 'juvenil' de autor decadentista de mera literatura decorativa. Sin embargo, Bernabé (2003: 43) desarticula esta tesis dualista analizando esas "polaridades antagónicas, para poder recuperarlo en su 'nomadismo', esto es, en las sucesivas transfiguraciones de su persona resistiendo a los esquemas establecidos". Ese nomadismo es el que funciona como bisagra entre las dos supuestas facetas del autor: en sus conferencias patrióticas por las provincias, que se realizan a modo de performance, encontramos el punto de unión entre lo que el autor 'representa' (se erige como portavoz de la juventud a través del discurso nacionalista y sociopolítico) y lo que 'presenta' (el poeta viste de manera extravagante, con sortijas en los dedos, proyecciones luminosas, en lugares insólitos).

En la figura del escritor-viajero, el poeta se pone él mismo en circulación. Más allá de sus libros, y en un medio en el que el libro veía dificultada su circulación, inicia una modalidad de oferta de su trabajo que reside en ser visto y oído por un auditorio. Literatura para el ojo y el oído, la práctica literaria valdelomariana juega con formas y procedimientos aptos para someter lo escrito a las exigencias propias de su performance oral (Bernabé 2003: 59).

Esta reivindicación de Valdelomar resulta muy acertada, en la medida en que Bernabé logra presentarlo como un autor integral, con un claro proyecto intelectual casi desde sus primeras obras. No podemos hablar ya de un Valdelomar costumbrista en oposición al primer dandy del Perú. La línea trazada por esta autora debe constituir, en mi opinión, un punto de partida para todo estudio sobre el poeta peruano, puesto que consigue situarlo como un precursor de la vanguardia y como el primero en darse cuenta de lo que el sistema capitalista exigía del nuevo tipo de escritor ajeno a la aristocracia tradicional. 
El viaje funciona, entonces, como motor de la modernidad en Valdelomar. No solo porque en él se aglutinan las dos facetas de su trayectoria, sino porque el viaje en sí mismo pone de manifiesto las contradicciones en las que se encontraba el escritor dentro del sistema. El viaje como modo de ganarse la vida y al mismo tiempo como huida y negación de lo que la sociedad exige al artista: "como el tuberculoso, el artista viajaba para alejarse del materialismo y vulgaridad modernos en busca del ideal artístico" (Nouzeilles 1998: 300). En palabras de Valdelomar:

Tan envilecidos estamos que ya no se concibe en el Perú que un hombre joven, de talento y optimista, sea capaz de emprender una campaña fundamentalmente patriótica y que se sacrifique y sufra muchas amarguras y muy crueles desengaños por tratar de sacar a buena parte de su país de la barbarie. Mientras muchos de mis compatriotas desdeñan el ideal y cultivan la ley del estómago, yo cultivo la ley de la belleza espiritual que consiste en sacrificar su juventud y los placeres de la vida por dedicar ambas cosas a la dura labor de difundir la cultura. Mientras muchos de mis compatriotas vegetan, sin ideales, esclavos de una labor que solo beneficia a su estómago, yo vivo libre, consagrado al culto de la Patria y al de la Belleza, los más bellos que puede concebir un hombre (Valdelomar 1985: 74). ${ }^{2}$

En oposición a esa impronta capitalista, la de la vulgaridad que encierra la labor "que solo beneficia a su estómago", el poeta Valdelomar sale de la metrópoli en busca de esos ideales modernistas que los autores de finales del siglo XIX se habían propuesto preservar. La búsqueda del ideal de belleza se encuentra con el culto a la patria, un culto que el poeta lleva a cabo desde sus primeras obras y no solo en los cuentos costumbristas posteriores a 1913. La creciente revalorización del capital simbólico autóctono se empieza a ver ya en 1911, en la breve novela La ciudad de los tísicos:

Si cabe idealismo en el arte, venid a buscarlo en los huacos. Venid a admirar símbolos, a interpretar miradas, a leer historias trágicas. ¡Interpretad la risa de los huacos! No busquéis la intensidad filosófica en ellos entre los que representan mazorcas de maíz o imitaciones de pelícanos, como no buscaríais ahora el arte entre las baratijas de un bazar de mercado. Id más arriba. Buscad el arte 'con vuestros propios ojos' (Valdelomar 2005: 16).

Valdelomar se refiere, con ese "id más arriba", a las figuras que representan caras, y específicamente a aquellos objetos cuyo motivo principal es la risa. Esa risa prehispánica que el autor peruano interpreta como una risa misteriosa y desconocida: "Y entre esos huacos simbólicos los hay que llegan hasta nosotros, indescifrables, mudos, misteriosos y en algunos hay que venir hasta Leonardo, hasta Goya, hasta Baudelaire, sí, hasta Baudelaire, porque esos objetos de barro son decadentes: ¡hay que verlos sonreír!" (Valdelomar 2005: 17). El personaje de esta breve novela se refugia en los museos urbanos, llenos de huacos prehispánicos, observándolos desde una mirada occidental y en los que encontramos "un tímido intento de apropiación local de la tradición decadente" (Nouzeilles 1998: 303). En efecto, Valdelomar lleva a cabo, ya en esta breve novela de juventud, una recuperación estética de huacos prehispánicos y del pasado colonial, trasladando así los valores decadentistas europeos al arte peruano, relocalizando esa mirada en una tradición nacional, pero sin perder la pose enfermiza del dandy occidental.

En el contexto de las vanguardias latinoamericanas se ha hablado a veces de un proceso de resemantización de la vanguardia europea, esto es, la reabsorción de

\footnotetext{
2 "El sentimiento nacionalista", conferencia dictada en Chiclayo.
} 
fenómenos artísticos foráneos en una realidad interna muy diferente. Así, lo que en Europa surge como respuesta al arte burgués, en Latinoamérica adquiere forzosamente otro cariz, en tanto que no existía un arte burgués a la manera europea. Algo similar sucede en la etapa previa a las vanguardias, la etapa que en Perú es protagonizada por Abraham Valdelomar, ese "mestizo provinciano que adoptó ante los letrados citadinos la pose arrogante del hombre cosmopolita. El suyo fue un gesto de quien asumió una modernidad ideal, paradigmática, ante un medio que percibía excluyente y lastrado por rancias convenciones de casta" (Elmore 1993: 13). ¿Cómo podía Valdelomar, este provinciano ajeno a las grandes familias limeñas, dueñas del panorama artístico nacional, adoptar la misma pose que un Baudelaire ante los burgueses parisinos? Obviamente, hubo una adaptación, en todos los sentidos y a todos los niveles:

También los poderosos, entonces, asumían un barniz de cosmopolitismo y contemporaneidad. La seducción de lo moderno no se limitó a esas capas medias, en gran parte provincianas, que pugnaban por encontrar su sitio bajo el sol ni a aquellos obreros anarquistas que aspiraban a crear una cultura autónoma y poner en cuestión el edificio social (Elmore 1993: 17).

En el juego entre modernidad y reivindicación de lo propio, Valdelomar abre esa vía del tratamiento artístico del mundo andino que será, como afirma Elmore, rápidamente clausurada: el indigenismo de los años veinte quiso ir más allá de la visión del pasado prehispánico como una suerte de historia exótica y legendaria del país (aunque no siempre lo consiguió). Sin embargo, Valdelomar ofrece a sus contemporáneos por un lado una visión muy lúcida del desarrollo del capitalismo, con los magníficos "cuentos yanquis", y por otro lado la revalorización de una tradición propia como estandarte para comenzar a definir la nacionalidad. Arroyo (1996: 94) ha afirmado que el "incaísmo" de la generación de Valdelomar "no va más allá de la fina intuición o la buena voluntad de algunos de sus integrantes". Sin embargo, en cierto sentido Valdelomar constituye una excepción, pues sus intuiciones producen interesantes cortocircuitos dentro del sistema literario nacional. La resemantización que realiza de los temas foráneos le permite construir un imaginario sin el cual no hubieran sido posibles algunos de los caminos que tomó la literatura peruana posterior.

Los cuentos incluidos en Los hijos del sol (publicado póstumamente, en 1921) son los que más nos interesan en ese sentido. El relato "El camino hacia el sol" ofrece todas las claves para comprender esta relectura de lo ajeno desde un punto de vista propio. Este cuento se sitúa en el momento de la conquista española del territorio andino: al enterarse de la llegada de estos hombres extraños, un pueblo entero, situado en un lugar indefinido de los Andes, decide emprender un viaje al santuario de Pachacámac, la "mansión del Sol", donde su dios los recibirá y los ayudará frente a los invasores. De este modo, los habitantes abandonan en procesión su pueblo, desesperados en busca de la ayuda divina; cruzan los Andes, llegan a los valles que anuncian ya la costa y, por fin, avistan el océano, "esa gran laguna en la cual se acuesta el Sol". Pero al llegar a la orilla se encuentran con un problema:

El entusiasmo del pueblo desapareció súbitamente. ¿Cómo irían ellos a atravesar ese inmenso río, para poder llegar adonde estaba el Sol? La víspera estaban ciertos de haberlo visto ocultarse entre las aguas, era, pues, seguro que llegando al sitio donde lo vieron hundirse, entrarían en su reino. Pero, ¿cómo atravesar esa laguna verde, rugiente, inmensa y enorme?... (Valdelomar 2003: 147). 
Aguardan en la orilla, seguros de que su padre el Sol irá a buscarlos, pero tras unos días de espera se dan cuenta de que su dios no los salvará: "El Sol nos ha abandonado". Deciden, entonces, cavar tumbas para todo el pueblo y entregarse al "último viaje" para reunirse con sus antepasados a la manera inca: enterrándose vivos.

Hay varios elementos importantes en este cuento. Lo primero que llama la atención son las resonancias bíblicas: el éxodo de todo un pueblo en búsqueda de la ayuda divina. En este caso, el pueblo busca a su dios el Sol, que en el imaginario presentado por Valdelomar es un dios único, falso monoteísmo atribuido a los incas ya desde el Inca Garcilaso de la Vega (a quien nuestro autor leyó). Este éxodo bíblico, sin embargo, se sitúa en el altiplano andino, recorre el paisaje peruano y llega a la costa, donde el mar actúa como barrera. El mar, sorprendentemente desconocido por este pueblo, esa gran laguna o río sin orillas, precipitará la decisión colectiva final. La ingenuidad que Valdelomar atribuye al pueblo es típica de la época, y sin ella sería difícil llevar a cabo la idealización de la vida andina que encontramos en el relato. Al comienzo del cuento, el pueblo indígena vive en una especie de idilio que se ve interrumpido por la llegada de los españoles y, en su ingenuidad, decide ir a la casa del Sol sin saber, aparentemente, lo que es el mar.

Por otro lado, un hilo conductor recorre el cuento: el amor entre Sumaj e Inquill, una pareja que, antes del éxodo, estaba esperando contraer matrimonio. Realizan el viaje juntos y es a través de sus ojos como conocemos el desarrollo de todos los acontecimientos narrados. El tema del matrimonio, así como la historia de amor que esta pareja representa, también ofrecen datos de interés en esta resemantización de ideas occidentales dentro del imaginario andino. Al final, en el suicidio colectivo que nos presenta el autor, la pareja será la última en morir. Tras enterrar a su amada Inquill, Sumaj permanece unos momentos sobre todas estas tumbas cerradas donde descansa un pueblo entero; permanece solo, callado, pensativo. Valdelomar presenta a Sumaj como la versión peruana del héroe romántico:

Cuando Sumaj dio la última paletada de tierra sobre el cuerpo, tuvo una extraña sensación. Ya no podía hablar. Nadie le escucharía. Entonces tuvo un impulso de enterrarse a sí mismo. ¿Pero cómo se enterraría? Fue sobre la tumba de Inquill, su adorada, y lloró largamente. El Sol empezaba a a caer. Entonces sintió una sensación que nunca había sentido. Por primera vez tuvo quejidos que se mezclaban con el rumor de las olas. Él era el único sobreviviente de aquel pueblo abandonado por la generosidad divina. Quiso abrir la fosa de su amada para unirse a ella, pero el temor de interrumpir su sueño lo detuvo (Valdelomar 2003: 152).

Esta breve escena final, en la que encontramos al héroe individual solo, enamorado, nostálgico, reflexionando sobre la muerte y el abandono de dios, podría pertenecer a cualquier relato romántico. El tema del suicidio es quizá lo más interesante del cuento: si por un lado la escena del amante llorando a la tumba de la amada, con el suicidio final, es típica de la fantasía decadentista y romántica, por otro lado, es bien conocida la costumbre andina de enterrar vivos a los parientes del Inca cuando este moría, para que lo acompañaran en su viaje. De manera que el suicidio se convierte, en manos de Valdelomar, en el punto de cruce perfecto entre la tradición literaria occidental y ciertas costumbres nacionales.

El autor peruano, en su búsqueda del "paradigma de lo moderno", encuentra el motivo ideal que permite la traducción de lo ajeno dentro de las condiciones específicas del medio propio. Se cumple aquí perfectamente lo que Elmore (1993: 39) recuerda sobre este tipo de traducción: "no es una copia, sino una re-lectura". Valdelomar ofrece una relectura impecable de aquellas corrientes literarias foráneas en el contexto de unas 
costumbres propias que son, en definitiva, reivindicadas. Sin embargo, la reivindicación no se hace de una cultura nacional contemporánea, sino de la historia pasada de una civilización conquistada. La idealización del imperio incaico permite al autor rescatar elementos de lo propio que nada tienen que ver con lo propio contemporáneo: serán los indigenistas quienes traten, con mayor o menor éxito, de poner en el centro la cultura nacional de la época, en lugar de un pasado idealizado que no puede sustituir a la modernidad que se impone desde fuera.

\section{BIBLIOGRAFÍA}

BERNABÉ, Mónica: "Dandismo y rebeldía en el Perú: el caso de Abraham Valdelomar", Iberoamericana, 3, 11 (2003), 41-63.

- (2006), Vidas de artista. Bohemia y dandismo en Mariátegui, Valdelomar y Eguren (Lima, 1911-1922). Rosario-Lima, Beatriz Viterbo, IEP.

ELMORE, Peter (1993): Los muros invisibles. Lima y la modernidad en la novela del siglo XX. Lima, Mosca Azul.

LOAYZA, Luis (1990): Sobre el 900. Lima, Hueso Húmero Ediciones.

_ (2003): "El joven Valdelomar", en Abraham Valdelomar, Los ojos de Judas y otros cuentos. Bogotá, Grupo Editorial Norma.

NOUZEILLES, Gabriela: "La ciudad de los tísicos: tuberculosis y autonomía", Anales de la literatura española contemporánea, 23, 1/2 (1998), 295-313.

NÚÑEZ, Estuardo: "Valdelomar y los orígenes de la vanguardia", Hispamérica, 20, 60 (diciembre 1991), 133-140.

RAMA, Ángel (1985): Rubén Dario y el modernismo. Caracas / Barcelona: Alfadil Ediciones.

RÉNIQUE, José Luis (2015): Imaginar la nación: Viajes en busca del "verdadero Perú” (1881-1932). Lima: IEP, Fondo Editorial del Congreso del Perú, Ministerio de Cultura.

SÁNCHEZ, Luis Alberto (1987): Valdelomar o la "belle époque”. Lima: Inpropesa.

VALDELOMAR, Abraham (1985): Las conferencias de Abraham Valdelomar. Recopilación, selección e introducción de César Ángeles Caballero. Ica, Editorial San Marcos.

_ (2003): Los ojos de Judas y otros cuentos, con ensayos de Luis Loayza y Ricardo Silva Santisteban. Bogotá, Grupo Editorial Norma.

\section{(C) Marta Ortiz Canseco}

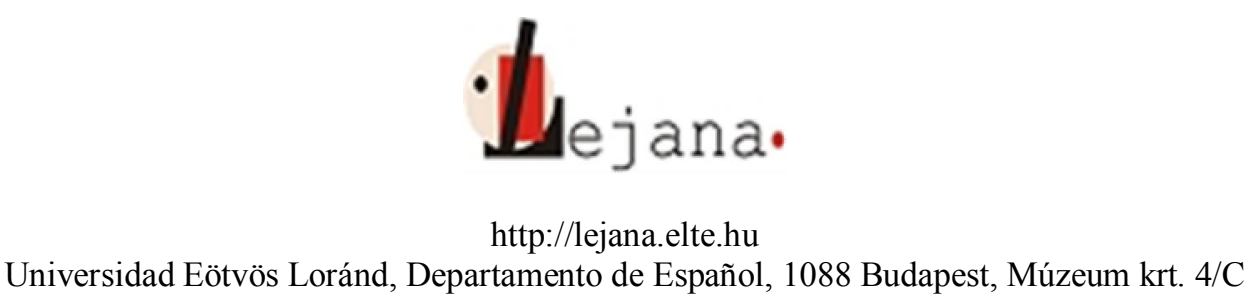

Recibido: 28 de septiembre de 2015

Aceptado: 13 de octubre de 2015 